\title{
Forum
}

\section{Hot under the collar: the failure of radio-collars on black rhinoceros Diceros bicornis}

\author{
Sky K. Alibhai and Zoë C. Jewell
}

\begin{abstract}
Radio-collaring is widely used as a monitoring tool in the conservation of the black rhinoceros Diceros bicornis. We examined rates and causes of radio-transmitter collar failure on black rhino in the Sinamatella Intensive Protection Zone (IPZ), Zimbabwe, between September 1993 and February 2000. Two collar designs, hose and strap, were fitted on immobilized rhinos in four main collaring operations. Eighty nine collars were monitored: 28 hose and 61 strap. Within 12 months of placement, all hose collars had failed. Of the strap collars, 73 per cent of those on males and 44 per cent on females had failed within 12 months. Failure rates were signifi-
\end{abstract}

\section{Introduction}

The black rhinoceros Diceros bicornis is categorized on the 2000 IUCN Red List (Hilton-Taylor, 2000) as critically endangered based on criteria $\mathrm{A} 1 \mathrm{abc}$ [i.e. population reduction (A) of at least 80 per cent over the last 10 years or three generations (1) based on direct observation (a) an index of abundance appropriate for the taxon (b) and a decline in area of occupancy, extent of occurrence and/or quality of habitat (c)]. Radio-collaring of black rhino was adopted by the Department of National Parks and Wildlife Management of Zimbabwe (DNP) in the early 1990s, for routine protection and monitoring (DNP, 1993).

The Veterinary Unit (VU) of the DNP (Veterinary Unit, 1995) reported collar losses on black rhino within the first 3 months of fitting, Cunningham \& Berger (1997) reported the loss of two out of three collars on black rhino in Etosha, Namibia and Hofmeyr (1998) the fates of 13 collars on black rhino in the Madikwe Game Park, South Africa. The repeated collaring of the population in the Sinamatella Intensive Protection Zone (IPZ) provided a large dataset on collar failure rates. Our aim here is to examine collar failure rates and

Sky K. Alibhai (Corresponding author) and Zoë C. Jewell Rhinowatch, Sinamatella Camp, P. Bag 5941, Hwange, Zimbabwe. Present address: Apartado 210, 8550-909 Monchique, Portugal.

E-mail: rhinowatch@clix.pt

Revised manuscript accepted for publication 6 June 2001 cantly higher in males for both collar types. For strap collars older males had higher failure rates than younger males. There was some evidence of a higher failure rate of strap collars during the wet season. Thirteen per cent of strap and 4 per cent of hose collars were removed because of poor transmission; 15 per cent of strap collars were removed because of injury. The implications of collar failure rates and the use of radio-collaring as a routine protection and/or monitoring strategy are discussed.

Keywords Diceros bicornis, radio-collaring, rhinoceros, telemetry, Zimbabwe.

contributory factors, and consider the efficacy of this technique as a long-term strategy for routine protection and/or monitoring of black rhino.

\section{Methods}

In the Sinamatella IPZ for the black rhino (Alibhai et al., 2001) four main collaring operations were conducted, in 1993, 1994, 1995 and 1997, by the DNP in conjunction with either their VU or the Veterinary Department of the Ministry of Lands, Agriculture and Water Resources. Materials, procedures and drugs were described by Kock \& Atkinson (1993) and the Veterinary Unit (1995, 1996). The 1997 operation was not reported but was similar to previous years (C. Foggin, unpublished data). Operations were usually undertaken towards the end of the dry season (September-November). Two smaller operations were undertaken on black and white rhino Ceratotherium simum in 1999. We undertook black rhino monitoring throughout these periods and assessed the failure rates of radio-collars.

Two radio-collar types were used (Veterinary Unit, 1995, 1996); strap collars (a leather strap with an elasticised insert strip) and hose collars (a pliable rubber hose covering a wire cable, fitted loosely around the neck). Both carried either a fibreglass or resin-embedded radio-transmitter. Hose collars were only used in 1994. Strap collars were used in all operations. The same fitting techniques and materials were used throughout. The radio-transmitters that were first used gave a constant intermittent audible bleep, whereas transmitters 
used subsequently gave a more frequent 'mortality' bleep when motionless for more than $6 \mathrm{~h}$.

Telonics TR4 and TR2 multi-channel hand-held radioreceivers, with Yagi rubber or metal antennae, were used to locate collared animals during aerial and ground monitoring. Three monitoring methods were used: aerial monitoring by the DNP at a mean frequency of once every 1.2 months during the study period, systematic ground monitoring approximately 3 times a week during the dry season (May-October) and at 2-4 week intervals during the rainy season (November-April) by ourselves working with scouts of the DNP, and patrolling by scouts in the IPZ almost every day during the study period during which sightings and collar status were recorded.

Radio-collars failed in four circumstances: firstly when they were found off a rhino, secondly, when they gave a 'mortality' signal (whether or not they were recovered), thirdly, when they had not been heard for several months of routine aerial and ground monitoring in which case 'last heard' signal date was retrospectively taken as failure date and/or where the animal had been seen without the collar, and fourthly, when they were removed from the animal due to injury, or because of a failing transmitter. The first three categories were termed 'natural failures' and the last category, 'removals'.

Veterinary teams attempted to age all individuals using standard techniques (Kock \& Atkinson, 1993; Veterinary Unit, 1995, 1996). Calves were assessed by size (Hitchins, 1970). Some adults were aged by dentition (Hitchins, 1978) and others by general VU assessment. When age assessment was not possible, the animal was described only as 'adult'. Rainfall data for the Sinamatella IPZ during the study period were provided by the DNP (B. Russell, unpublished data).

We assessed failure rates for the two collar types by plotting the cumulative percent failure over time. Using collar duration as the response variable, we examined the effects of independent variables (sex and age for hose collars; sex, age and year of fit for strap collars) in a general linear model (GLM). We analysed the data for the two collar types separately because hose collars were used only in 1994. Duration for strap collars was square root transformed to normalize the data. The effect of seasonality on strap collar failure was examined separately. Data were gathered from September 1993 until February 2000. Data gathered by the VU of the DNP during immobilization operations were made available to us by permission of the DNP.

\section{Results}

The fates of 89 radio-collars were monitored (Table 1): 28 hose collars ( 14 on males and 14 on females) and 61 strap collars (22 on males and 39 on females). Of these, one hose collar and eight strap collars were removed because of age or poor transmission, and nine strap collars were removed because of injury. Eight strap collars were never retrieved, and were considered lost after the last heard signal date. A total of 587 aerial signals and/or sightings of radio-collared black rhino and 1923 ground-tracking observations (signals and/or sightings) were made.

Figure 1 shows the cumulative percentage failure rates of hose and strap collars. All hose collars and 73 and 44 per cent of strap collars on males and females, respectively, failed within 12 months. Using a least squares regression GLM we examined the effects of collar type, sex and age on the failure rate of collars. The data were analysed using JMP Statistical Discovery Software (SAS Institute, 1995). Collar failure was much higher for hose collars than strap collars, males than females and older than younger animals (Table 2).

The possible effect of seasonality was more difficult to investigate because most of the collars ( 90 per cent) were fitted between September and December. However, when strap collar duration was plotted against natural log of collar 'survival' (Fig. 2) the pattern suggested that collar failure was possibly greater at the onset and during the wet season compared with the dry season.

Table 1 Collar type used, year of fit and the number of collars fitted for males and females and mean collar duration in months. For natural failures and removals, natural failures only and removals only.

\begin{tabular}{|c|c|c|c|c|c|c|c|}
\hline \multirow[b]{2}{*}{ Collar type } & \multirow[b]{2}{*}{$\begin{array}{l}\text { Year of } \\
\text { collar fit }\end{array}$} & \multicolumn{2}{|c|}{ Natural failures plus removals } & \multicolumn{2}{|c|}{ Natural failures only } & \multicolumn{2}{|c|}{ Removals only } \\
\hline & & $n(\mathrm{~m} / \mathrm{f})$ & $\begin{array}{l}\text { Mean duration } \\
\text { in months } \pm S E\end{array}$ & $n(\mathrm{~m} / \mathrm{f})$ & $\begin{array}{l}\text { Mean duration } \\
\text { in months } \pm \mathrm{SE}\end{array}$ & $n(\mathrm{~m} / \mathrm{f})$ & $\begin{array}{l}\text { Mean duration } \\
\text { in months } \pm \mathrm{SE}\end{array}$ \\
\hline Hose & 1994 & $28(14 / 14)$ & $4.61 \pm 0.53$ & $27(13 / 14)$ & $4.63 \pm 0.55$ & $1(1 / 0)$ & 4.00 \\
\hline Strap & 1993 & $7(0 / 7)$ & $12.29 \pm 3.74$ & $1(0 / 1)$ & 18.00 & $6(0 / 6)$ & $11.33 \pm 4.28$ \\
\hline Strap & 1994 & $10(5 / 5)$ & $8.00 \pm 1.98$ & $6(3 / 3)$ & $5.83 \pm 2.52$ & $4(2 / 2)$ & $11.25 \pm 2.75$ \\
\hline Strap & 1995 & $32(14 / 18)$ & $12.66 \pm 1.57$ & $27(13 / 14)$ & $11.74 \pm 1.72$ & $5(1 / 4)$ & $17.60 \pm 3.30$ \\
\hline Strap & 1997 & $12(3 / 9)$ & $11.42 \pm 2.37$ & $10(3 / 7)$ & $11.10 \pm 2.34$ & $2(0 / 2)$ & $13.00 \pm 11.00$ \\
\hline Strap total & $1993-97$ & $61(22 / 39)$ & $11.61 \pm 1.08$ & $44(19 / 25)$ & $10.93 \pm 1.26$ & $17(3 / 14)$ & $13.35 \pm 2.13$ \\
\hline
\end{tabular}



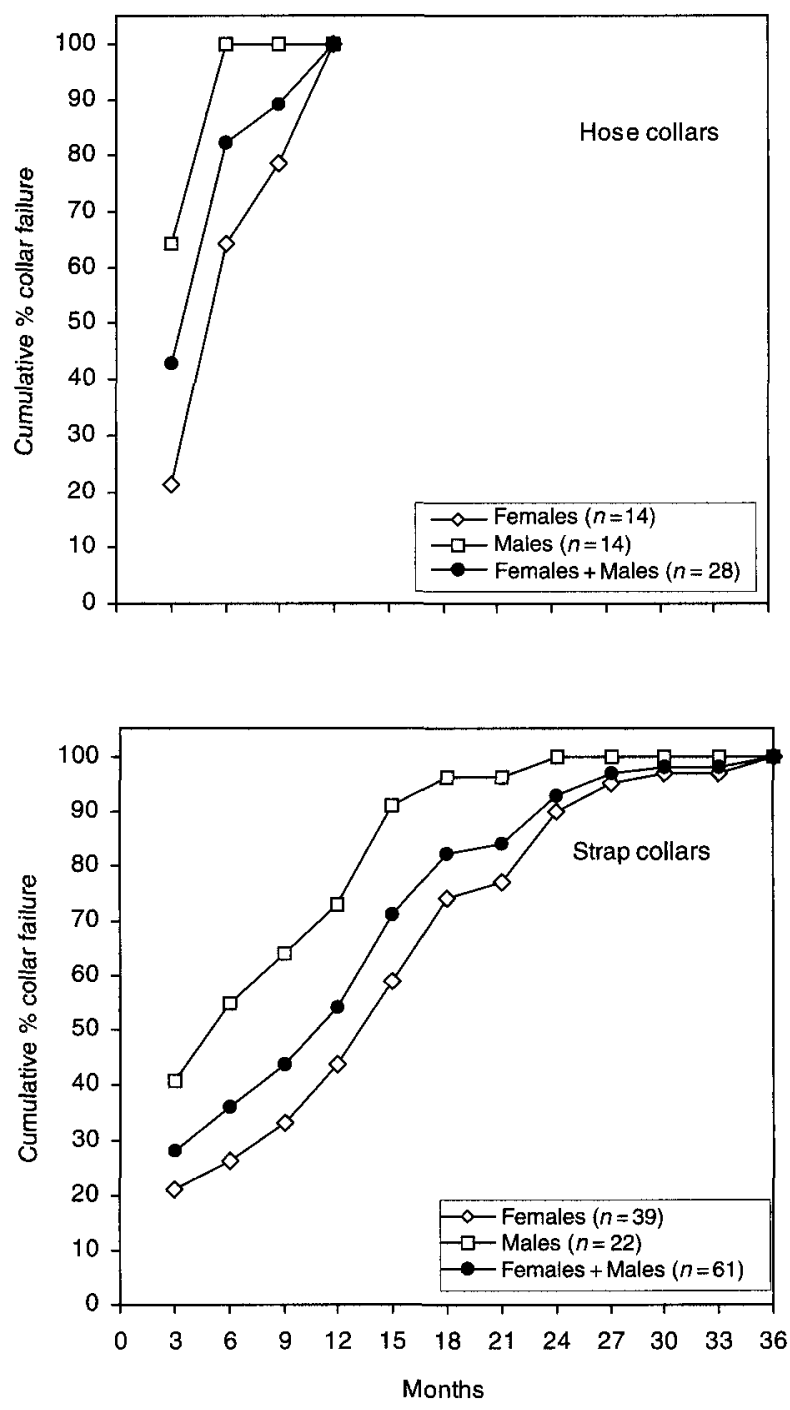

Fig. 1 Cumulative percentage failure of hose and strap radiocollars on black rhinos over 12 and 36 months, respectively.

Table 2 The effects of collar type, sex and age on collar duration using a general linear model. Natural failures only.

\begin{tabular}{lll}
\hline Effect & F-ratio & $P$ \\
\hline Sex & 7.76 & $<0.01$ \\
Age & 5.45 & $<0.05$ \\
Collar type & 4.07 & $<0.05$ \\
\hline
\end{tabular}

\section{Discussion}

In most rhino range states, radio-collaring is only used opportunistically when animals have to be translocated, or for temporary surveillance of a proportion of the population that is peripheral to the core population, and is not generally repeated when the collar fails (K. Adcock, pers. comm.). Zimbabwean IPZ's have unusually attempted to maintain collars on a wider

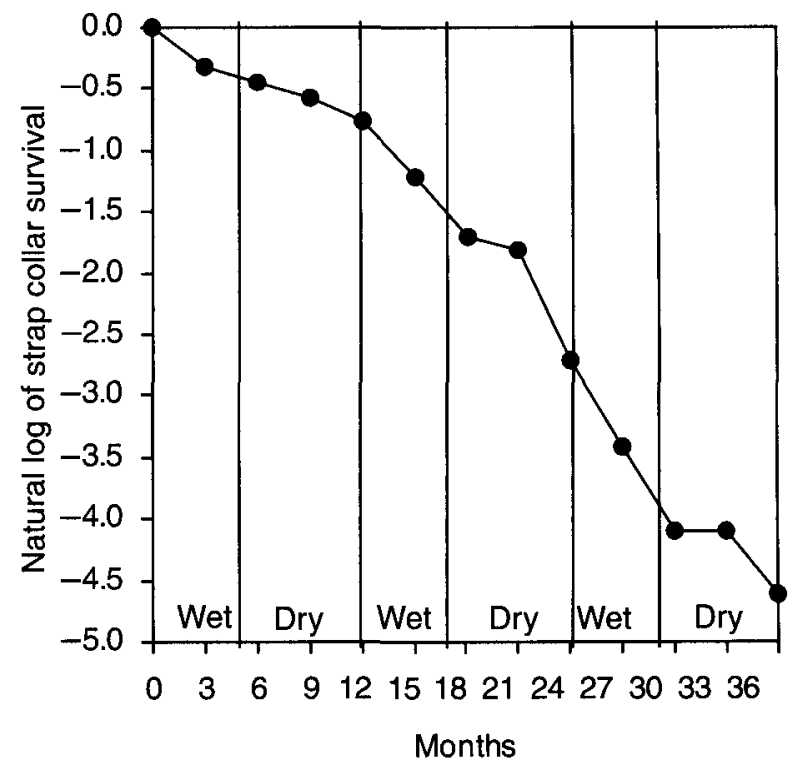

Fig. 2 The natural log of strap collar survival against time (months) in wet (November-March) and dry (April-October) seasons for all collared rhinos $(n=61)$.

population for an extended period and for routine monitoring and protection.

The projected failure rate of collars for an even sexratio population at Sinamatella is almost 60 per cent per annum. These results are not unique, however. Hofmeyr (1998) reported the collaring of translocated black rhino in the Madikwe Game Reserve in South Africa using four different transmitter types. The collar failure rate (calculated from Hoymeyr's Table 1) for this study (including three rhinos in the Kruger National Park) was 58 per cent at 12 months. Radio-collaring operations at Sinamatella in 1999 actually gave higher collar failure rates, although these operations have not been included in the present analysis because the methodology was different. Of eight collars fitted to black rhino in July 1999, 63 per cent had failed after 7 months, and of six white rhino collars fitted in May 1999, 100 per cent had failed by 9 months.

The Veterinary Unit (1996) suggested that a strap collar drop-off rate of $>10$ per cent per annum was unacceptable. We believe it is unlikely that this target can be achieved, despite continuing attempts to develop a more effective collar design. Rhino have a high neck : head width ratio that will not hold any collar unless it is tightly fitted, which means that irritation and injury can occur. In this study several collars were found in areas with physical disturbance consistent with attempts by the animal to remove the collar, and others were observed half-over the head. Fifteen per cent of collars had to be removed because of abrasion or laceration injuries. The Veterinary Unit (1996) noted that 
longer surviving collars were those that had not caused noticeable damage to the animals. Hofmeyr (1998) reported that the neck circumference of an immobilized black rhino varied by $15 \mathrm{~cm}$ depending on posture, and thus even if a non-irritating collar could be designed, an ideal fitting would be extremely difficult.

Higher failure rates for males may result from their higher neck: head width ratio, a lower tolerance to irritation or greater strength. With respect to a potential effect of season, wet collars are more likely to rot or slip off, but irritating collars will also be shed as soon as possible after fitting, which usually coincided with the rainy season in this study. It is also possible that an increase in body condition during the rains led to increased failure by breakage. Hofmeyr (1998) reported that collar fit varied with condition, and our observations and data concur.

This study has highlighted five possible contra-indications to routine radio-collaring:

- Cost. It is an expensive option for routine protection and monitoring (Kock \& Atkinson, 1993; Alibhai et al., 1996), both for fitting and for follow-up monitoring, and is unlikely to be sustained by developing countries with limited conservation budgets.

- Welfare. Fifteen per cent of collars caused wounding. Plate 1 shows the extent of injury that can be caused by a strap collar. This wound, on a white rhino at Sinamatella, was estimated to be several months old, but was identified only a week before the collar was removed. Lesser collar wounds also attracted attention from spotted hyaena Crocuta crocuta. Thirteen per cent of strap collars were not located after 'last heard' dates. Their fate remains unknown and constitutes a further welfare concern.

- Security. We believe that routine collaring may induce a false sense of security in rhino managers; collar failure rates are high and there is no direct evidence that collaring protects animals from poachers. Also, because it is an expensive and time-consuming technique, more effort and funding may be diverted into the protection of collared animals than uncollared ones.

- Compromise of female fertility. The chemical immobilization required for collar fitting may significantly compromise the fertility of female black rhino (Alibhai et al., 2001).

- Difficulty in maintaining sufficiently frequent followup monitoring. Monitoring involves considerable expertise and time, and may present particular difficulties where a transmitter has failed but a collar

Plate 1 A wound on a white rhino at Sinamatella. (A) Chronic abrasion and laceration with severe oedema around the ears and head; (B) Deep laceration on the ventral side of the neck.
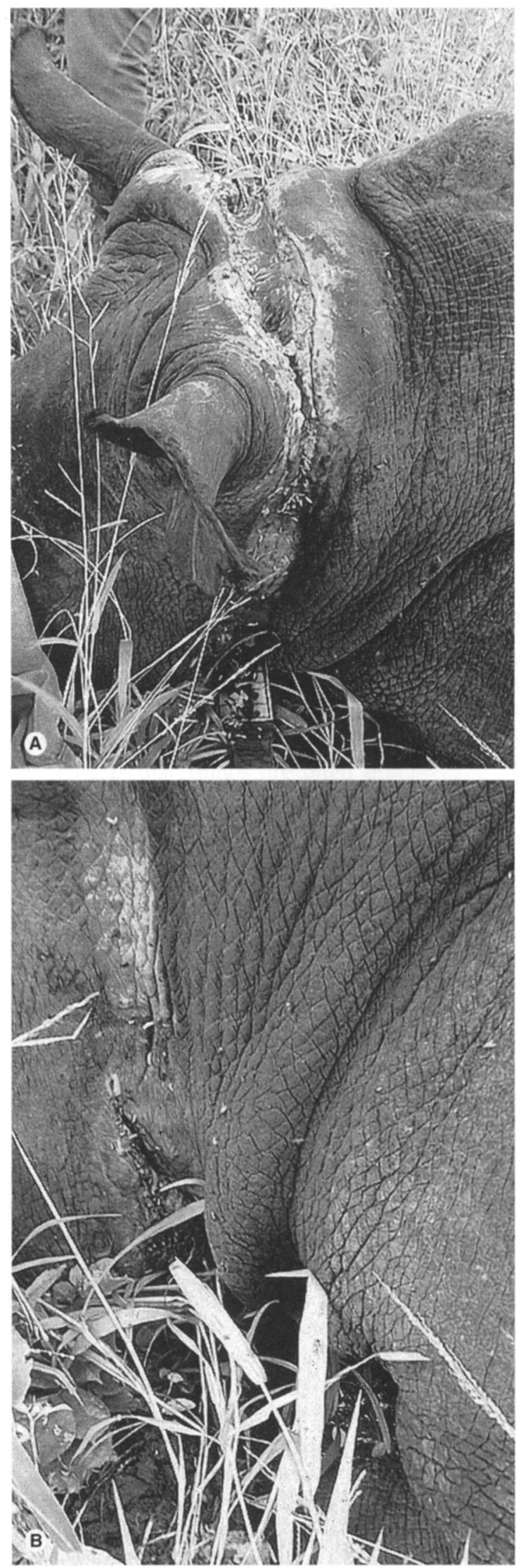
is still in place. We suggest a sighting of each collared animal once a week as a minimum requirement. Radio-collaring is only as effective as the frequency and quality of monitoring activities.

In conclusion, we suggest that routine radio-collaring of rhino for protection and monitoring is not an effective long-term strategy. We also suggest that common guidelines on fitting and monitoring should be adopted for those circumstances in which any collaring is to be used.

\section{Acknowledgements}

We thank the Department of National Parks and Wild Life Management of Zimbabwe, especially the late Area Ecologist, Stewart Towindo, Dr Peter Mundy and Mrs Beatrice Russell, and the Scouts at Sinamatella. We also thank our corporate sponsor SAS, The Earthwatch Institute, a generous anonymous donor, Dr Pete Law and four anonymous referees.

\section{References}

Alibhai, S.K., Jewell, Z.C. \& Towindo, S.S. (1996) The Density, Distribution and Ranging of the Black Rhino (Diceros bicornis) in the Sinamatella Intensive Protection Zone, Hwange National Park, Zimbabwe. Report to the Department of National Parks and Wild Life Management of Zimbabwe.

Alibhai, S.K., Jewell, Z.C. \& Towindo, S.S. (2001) The effects of immobilization on fertility in female black rhino (Diceros bicornis). Journal of Zoology, 253, 333-345.
Cunningham, C. \& Berger, J. (1997) The Horn of Darkness, Rhinos on the Edge. Oxford University Press, New York.

Department of National Parks and Wild Life Management of Zimbabwe (1993) Black Rhino Conservation Project - Emergency Plan 1993. Report of the Department of National Parks and Wild Life Management of Zimbabwe.

Hilton-Taylor, C. (Compiler) (2000) 2000 IUCN Red List of Threatened Species. IUCN, Gland, Switzerland \& Cambridge, UK.

Hitchins, P.M. (1970) Field criteria for ageing immature black rhinoceroses, Diceros bicornis L. Lammergeyer, 12, 48-55.

Hitchins, P.M. (1978) Age determination of the black rhinoceros (Diceros bicornis Linn.) in Zululand. South African Journal of Wildlife Research, 8, 71-80.

Hofmeyr, M. (1998) Comparison of four different radio-transmitter attachments on black rhino in Madikwe Game Reserve (June 1996-October 1998). Pachyderm, 26, 14-24.

Kock, M. \& Atkinson, M. (1993) Report on Dehorning of Black (Diceros bicomis) and White (Ceratotherium simum) Rhinoceroses in Zimbabwe. Report by the Department of National Parks and Wild Life Management of Zimbabwe.

SAS Institute (1995) JMP Statistics and Graphics Guide. SAS Institute, Cary, NC, USA

Veterinary Unit (1995) Immobilisation, Dehorning, Radio-collaring/ Monitoring, and Health Problems of Black and White Rhinoceros in the Matobo, Sinamatella and Matusadona Intensive Protection Zones, 1994. Report by the Department of National Parks and Wild Life Management of Zimbabwe.

Veterinary Unit (1996) Immobilisation and Radio-collaring of Black Rhinoceros in the Sinamatella Intensive Protection Zone (IPZ), Hwange National Park and Matusadona National Park IPZ. A report. Report by the Department of National Parks and Wild Life Management of Zimbabwe. 